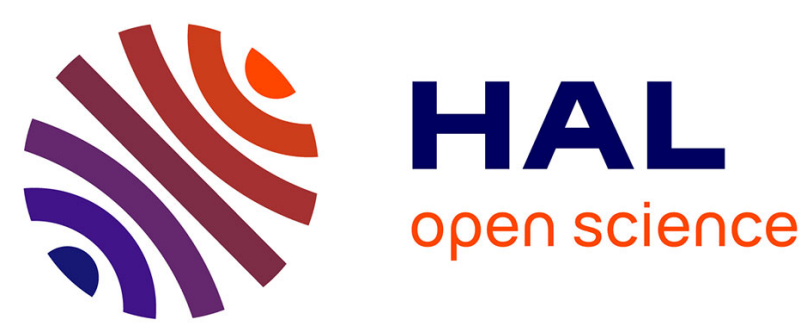

\title{
VIBRATIONAL PROPERTIES OF VACANCIES IN HOMOPOLAR SEMICONDUCTORS
}

\author{
K. Suzuki, D. Schmeltzer, A. Maradudin
}

\section{To cite this version:}

K. Suzuki, D. Schmeltzer, A. Maradudin. VIBRATIONAL PROPERTIES OF VACANCIES IN HOMOPOLAR SEMICONDUCTORS. Journal de Physique Colloques, 1981, 42 (C6), pp.C6-640-C6-642. 10.1051/jphyscol:19816186 . jpa-00221269

\section{HAL Id: jpa-00221269 https://hal.science/jpa-00221269}

Submitted on 1 Jan 1981

HAL is a multi-disciplinary open access archive for the deposit and dissemination of scientific research documents, whether they are published or not. The documents may come from teaching and research institutions in France or abroad, or from public or private research centers.
L'archive ouverte pluridisciplinaire HAL, est destinée au dépôt et à la diffusion de documents scientifiques de niveau recherche, publiés ou non, émanant des établissements d'enseignement et de recherche français ou étrangers, des laboratoires publics ou privés. 


\title{
VIBRATIONAL PROPERTIES OF VACANCIES IN HOMOPOLAR SEMICONDUCTORS
}

\author{
K. Suzuki, D. Schmeltzer and A.A. Maradudin \\ Max-Planck-Institut für Festkörperforschung, Heisenbergstrasse 1, 7000 \\ Stuttgart $80, F \cdot R \cdot G$.
}

\begin{abstract}
Spectral densities of phonons in the immediate vicinity of a vacancy in Si and Ge are calculated in the continued fraction/recursion method. The results indicate that both in $\mathrm{Si}$ and $\mathrm{Ge}$ the presence of vacancy gives $r$ ise to a sharp decrease in the COS in the optical frequency range and a rather diffuse increase in the acoustic frequency range.
\end{abstract}

1. Introduction. - At moderately high concentrations of hydrogen in amorphous $\mathrm{Si}$, four hydrogen atoms tend to cluster as they saturate groups of four dangling bonds pointing towards a counterpart of the crystalline vacancy. ${ }^{1}$ Infrared absorption ${ }^{1,2}$ and Raman scattering ${ }^{3}$ experiments on amorphous and crystalline si or Ge vith H, D, or $\mathrm{F}$ as impurities show that the frequency of the resonant vibration in the acoustic range depends only very slightly on impurity species. This sungests that such vibrational modes involve a large number of atoms of the host and leads one to suspect that the vacancy in whose vicinity the clustering occurs may itself give rise to resonant modes in the frequency range where they have been observed.

As a step in the direction of elucidating the nature of the resonant modes we have studied vibrational properties of crystalline $\mathrm{Si}$ and Ge containing an isolated vacancy. Lse has been made of the real space version of the continued fraction/recursion method ${ }^{4}$, which does not require a periodic arrangement of atoms. The method has been applied successfully to several types of lattice dynamical defect problems involving a lowering of symetry ${ }^{5}$, a though not to point defects as far as we are aware.

The local density $\rho_{a \alpha}(\ell, \ell ; \omega)$ of vibrational modes of polarization $\alpha$ at site $\ell$ and frequency $\omega$ is directly related to the diagonal element of the Green's function of the dynamical matrix $D_{\alpha \beta}\left(l, l^{1}\right)^{6}$. In the recursion method ${ }^{4}$ the latter is expressed in a continued fraction

$$
u_{\alpha \alpha}(l, l ; \omega)=\frac{1}{\omega^{2}-a_{0}-\frac{b_{0}^{2}}{\omega^{2}-a_{1}-\frac{b_{1}^{2}}{\omega^{2}-a_{2} \cdots}}},
$$

where the coefficients $\left(a_{0}, a_{1}, \ldots\right)$ and $\left(b_{0}, b_{1}, \ldots\right)$ can be obtained as functions of $\ell$ and $\alpha$ algebraically once $D_{\alpha \beta}\left(\hat{x}, \ell^{\prime}\right)$ of the system is given. 
2. Perfect Crystal. - To examine the applicability of the recursion method we first calculate the phonon spectrum of Si crystal without vacancy. On the one hand the phonon spectrum is obtained in the recursion method by considering a finite crystal containing up to 18000 atoms, at the surface of which all bonds are terminated. The dynamical matrix is such that includes only the first and second neighbor forces. 7 This requires six independent force constants, of which five have been chosen to give a best least-squares $f i t$ to the experimental phonon frequencies at $\Gamma, X$, and $L$ points. ${ }^{8}$ The last one, the second neighbor force constant $\delta$, which affects none of the above phonons, has been either fixed on the basis of the valence force field mode $1^{9}(\delta=(\mu-\nu-\lambda) / 2)$ or equated to zero. The first 21 coefficients $\left(a_{0}, \ldots, a_{20}\right)$ and $\left(b_{0}, \ldots, b_{20}\right)$ in Eq. (1) were directly calculated and the rema ining part of the continued fraction was replaced by an asymptotic form

$$
T=\left\{\omega^{2}-a_{\infty}-\left[\left(\omega^{2}-a_{\infty}\right)^{2}-4 b_{\infty}^{2}\right]^{1 / 2}\right\} /\left(2 b_{\infty}^{2}\right)
$$

where $a_{\infty}$ and $b_{\infty}$ are chosen either from an extrapolation of the calculated coefficients or from the requirement that the obtained phonon spectrum extends from zero to the experimental highest frequency (namely that of the optical phonons at $\Gamma$ ). The phonon LCOS $\rho_{\alpha \alpha}(\ell, l ; \omega)$ calculated from Eq. (1) is independent of $a$ and $\ell$ (provided $\ell$ is close to the center of cluster) and is represented by the upper curve in Fig. 1.

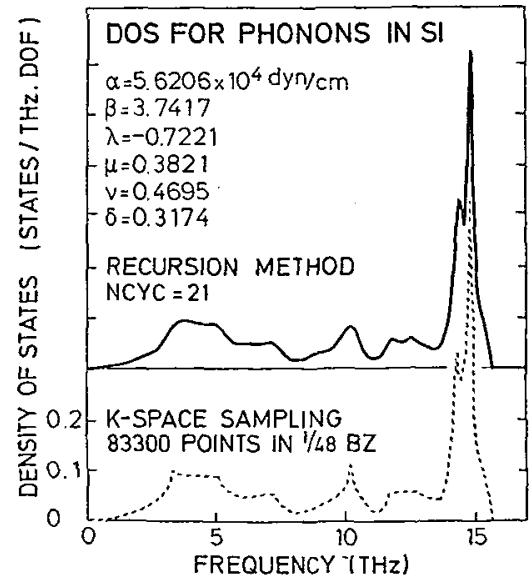

Fig. 1. Lattice vibration spectrum of si using first and second neighbor forces in the recursion and in the k-space sampling method. The force constants are those defined by Herman.
On the other hand the phonon spectrum is calculated for an infinite lattice using the same force constants in the usual $k$-space sampling method. With about 80000 sample points in $1 / 48$ of the Brillouin zone we obtain a phonon DOS which is shown by the lower curve in Fig. 1 .

With only up to second neighbor forces neither of the DOS reproduces the sharp peak in the acoustic region which would be present if the substantial flattening of acoustic phonons in the vicinity of $B Z$ edge were properly taken into account. ${ }^{10}$ Except for this, both of the curves reproduce the general features of the known phonon spectrum fairly well. The two curves are very similar, the only difference being that the recursion method generally smoothes sharply edged van Hove singularities characteristic of infinite crystals. 11 
3. Vacancy. - To model a vacancy in the simplest way we remove the central Si atom at $l=0$ and equate to zero all forces connected to this atom. In contrast to the preceding case, the LDOS does depend on the lattice site $\ell$ and we evaluate it at one of the four nearest neighbors of the vacancy. The recursion calculation proceeds in a similar way as before using the same set of force constants, except that we equate $\delta=0$, which is required if the translational invariance condition ${ }^{6}$ is to be satisfied without introducing new force constants. No relaxation of atomic position is assumed. The spectral density for the perfect crystal $(\delta=0)$, that of the vacancy and their difference are shown in Fig. 2 .

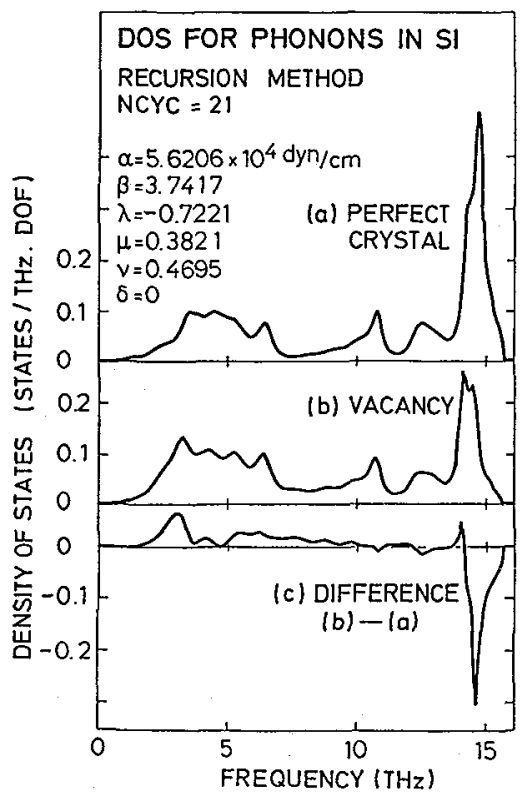

Fig. 2. Vibration spectrum of the singte vacancy in Si calculated in the recursion method.
4. Discussion. - In Fig. 2 we see a diffuse increase of DOS in the lower acoustic frequency region and a decrease in the optical region. This is expected if we consider the presence of a vacancy as a partial softening of the force acting on $i$ ts neighbors. The introductior of $\mathrm{H}$ or $\mathrm{F}$, on the other hand, corresponds to a hardening (decreased ionic mass) and gives rise to a rather sharp resonant mode at the upper edge of the acoustic spectrum, as has been observed. A further discussion on the change of DOS for various point defects can be made on the basis of the function ( 1 ) for the perfect crystal. Essentially similar results are obtained for a vacancy in Ge.

5. Acknowledgement. - We are indebted to M. Cardona, H. Bilz, and W. Kress for discussions and to H.J. Stärke for advice on numerical work.

\section{References}

1. S.C. Shen, C.J. Fang, M. Cardona, and L. Genzel, Phys. Rev. B 22, 2913 (1980).

2. H. Shanks, C.J. Fang, L. Ley, M. Cardona, F.J. Demon, and S. KâTbitzer, Phys. Stat. So 1. (b) 100, 43 (1980);

S.C. Shen, C.J. Fang, and M. Cardona, Phys. Stat. Sol. (b) 101, 451 (1980).

3. D. Bermejo and M. Cardona, J. Noncryst. Solids 32, 405 (1579).

4. R. Haydock, Solid State Phys. 35, 215 (1980), M.J. Kelly, ibid 35, 295 (1980).

5. M. Mostoller and U. Landman, Phys. Rev. B 20, 1755 (1979), J.E. Black, B. Laks, and D.L. Mills, Phys. Rev. B 22, 1818 (1980).

6. A.A. Maradudin et al., Sol id State Phys. Suppl. 3 (2nd ed.), 1 (1971).

7. Our notation of force constants is the same as F. Herman, J. Phys. Chem. Solids $8,405(1959)$.

8. H. Bilz and W. Kress, Phonon Dispersion Relations in Insulators, Springer, 1979.

9. K. Kunc, H. Balkanski, and M. Nusimovici, Phys. Rev. B 12, 4346 (1975).

10. W. Heber, Phys. Rev. B 15, 4789 (1977).

11. Similar conclusions have been obtained for a simpler case by P.E. Meek, Phil. Mag. 33, 897 (1976). See also C. Herscovici and M. Fibich, J. Phys. C 13, 1635 (1980) and V. Heine, Solid State Phys. 35, 1 (1980). 